\title{
Pemberdayaan Ekonomi Kreatif melalui Pemanfaatan Limbah Styrofoam Menjadi Barang Bernilai Ekonomis di Kampung Sentra Pengrajin Mainan Pesawat Terbang
}

\author{
Lukman Harahap \\ IAIN Surakarta \\ E-mail: gus.lukman@gmail.com
}

\author{
Muhammad Husin Al Fatah \\ IAIN Surakarta \\ E-mail: fatah1912abdullah@gmail.com
}

\section{Layyin Mahfiana \\ IAIN Surakarta \\ E-mail: layin.oke@gmail.com}

\section{Article History:}

Received: 2019-12-19

Revised: 2020-03-11

Accepted: 2020-05-31
Keywords: Styrofoam Waste, Miniature Aircraft, Creative Economic Empowerment

\begin{abstract}
Surakarta is a vocational city actively promoting the community uniqueness to be managed in the form of social, cultural and economic activities. IAIN Surakarta Research and Service Institute (LP2M) team has trained the people of Debegan village, Mojosongo, Surakarta City to make miniature aircraft using styrofoam materials. This community service was intended to provide access to creative economic empowerment for village communities. The method applied was Participation Action Research (PAR). The results showed that the program received relatively good enthusiasm from the people. The level of attendance and frequency of the attended meeting was always more than 20 out of 30 participants. This shows that the $80 \%$ target audience attendance was reached successfully. This activity requires further follow up to the training that has been given, with the hope that the community will not only be skilled in making crafts from Styrofoam waste but also have marketing and network skills.
\end{abstract}

\section{Pendahuluan}

Perubahan sosial berpotensi terjadi dalam suatu kelompok masyarakat dalam kurun waktu tertentu, baik dalam skala makro maupun mikro. Bagi masyarakat adanya perubahan tersebut dapat dipandang sebagai suatui kemajuan atau kenunduran bergantung dari berbagai dimensi yang dititikberatkan. Bentuk perubahan di dalam masyarakat dapat berupa nilai sosial, pola-pola pikir dan perilaku, persepsi terhadap suatu hal, lembaga dan struktur masyarakat, pola kekuasaan, dan interaksi sosial. Adanya perubahan itu dapat dipengaruhi oleh faktor-faktor modernitas yang merujuk pada kemajuan ilmu pengetahuan dan teknologi. Perubahan sosial merupakan 
perubahan yang terjadi dalam struktur kehidupan manusia diyakini sebagai suatu peristiwa yang mempunyai proses atau mekanisme tertentu. Terjadinya proses perubahan sosial itu dapat disebabkan beberapa faktor, yaitu kontak dengan budaya lain, sistem pendidikan formal yang maju, sikap menghargai basil karya seseorang dan keinginan untuk maju, toleransi, dan sistem terbuka ${ }^{1}$.

Dinamika sosial yang terus berkembang dari waktu ke waktu merupakan fenomena yang menarik untuk diamati dan ditelaah. Tidak dapat dipungkiri bahwa masyarakat heterogen ini turut membawa perubahan signifikan pada pola kehidupan masyarakat itu. Keterbukaan arus informasi dan sikap permisif merupakan aspek yang sangat mendukung gejala perubahan sosial itu. Adanya perubahan sosial dipandang tidak menjadi persoalan pelik ketika tidak menimbulkan benturan-benturan di masyarakat, yakni tidak bertentangan kebiasaan-kebiasaan tertentu yang sudah terpola. Namun demikian, ketika perubahan itu terdapat hal-hal yang bertentangan dengan kebiasaan yang sudah melembaga umumnya akan menimbulkan konflik. Sementara itu, masyarakat sering dihadapkan pada pilihan-pilihan yang "dilematis" ketika menerima hal-hal baru. Oleh karena itu, perlu adanya suatu mekanisme yang tepat untuk menjembatani arus perubahan sosial tersebut.

Salah satu masalah klasik dalam menghadapi dinamika sosial tersebut adalah tentang pengelolaan sampah dalam masyarakat kita. Pesatnya perkembangan teknologi, ternyata tidak serta merta membuat masyarakat memiliki kesadaran tentang lingkungan yang baik. Banyaknya limbah-limbah rumah tangga yang dihasilkan oleh masyarakat, mengakibatkan buruknya kualitas lingkungan yang dapat mengakibatkan sumber penyakit (cari sumber tentang lingkungan). ${ }^{2}$

Salah satu limbah yang memiliki kandungan zat kimia berbahaya dan sulit untuk diuraikan adalah limbah Styrofoam. Styrofoam merupakan salah satu sampah yang tidak bisa diuraikan oleh alam. Data EPA (Enviromental Protection Agency) di tahun 1986 menyebutkan, limbah berbahaya yang dihasilkan dari proses pembuatan styrofoam sangat banyak. Seperti, CFC yang merupakan senyawa gas yang disebut sebagai penyebab timbulnya lubang ozon di planet Bumi. Padahal, di sisi lain, jumlah limbah organik di Indonesia sangat melimpah dan mudah kembali ke alam tetapi kurang dimanfaatkan ${ }^{3}$.

Untuk pemanfaatannya, Styrofoam dapat diubah menjadi berbagai produk baru berbekal kreatifitas. Di China, limbah Styrofoam digunakan untuk membuat dekorasi lampu cantik. Sedangkan di Jepang, masyarakatnya telah mengenal terminologi baru

${ }^{1}$ Soerjono Soekanto, Teori Sosiologi Tentang Perubahan Sosial (Ghalia Indonesia, Jakarta, 1983).

2 Amang Fathurrohman et al., Inisiasi Tata Kelola Manajemen Bank Sampah Berbasis IT Pada Komunitas Bank Sampah Berbasis Sekolah, Pemuda, Dan Masyarakat Di Kabupaten Pasuruan (Kabupaten Pasuruan, 2018).

3 Aninditya Wisnuputri, Denny Nurkertamanda, and Wiwik Budiawan, "Pemanfaatan Limbah Organik Tumbuhan Dan Hifa Fungi Rhizopus Sp. Pada Struktur Bantalan Kemasan Barang Dengan Metode Eksperimen Faktorial" 3 (2014). 
untuk hasil olahan Styrofoam, mereka menyebutnya Styrogami. Styrogami adalah sebuah kreasi yang mengolah Styrofoam menjadi benda-benda unik. Ide ini terinspirasi dari origami. Selain itu, Styrofoam juga bisa dimanfaatkan untuk membuat souvenir gelas unik, hiasan rumah, pengeras suara laptop, vas bunga, media printing, beauty dish, dan kerajinan miniatur pesawat terbang. ${ }^{4}$

Dari berbagai urian diatas tentang Limbah Styrofoam, kami melaksanakan kegiatan pendampingan pengabdian masyarakat di wilayah Urban Kota Surakarta, Dusun Debegan, Mojosongo, Jebres, Surakarta. Kegiatan ini memberikan fasilitasi terhadap masyarakat Debegan Mojosongo Surakarta dalam mengelolala limbah Styrofoam menjadi kerajinan miniatur pesawat terbang. Dengan pertimbangan bahwa salah satu warga di dusun tersebut memiliki potensi untuk pengembangan kerajinan miniature pesawat tersebut. Sehingga pada akhirnya masyarakat dapat mengembangkan potensi ekonomi kreatif dengan memaksimalkan potensi tersebut.

Sesuai dengan semangat Kota Surakarta sebagai kota Vokasi, kegiatan pengabdian masyarakat di dusun Debegan ini bertujuan untuk membentuk wilayah Kampung vokasi kerjinan miniatur pesawat berbahan limbah Styrofoam. Dengan adanya kampung wisata tersebut, maka akan terjadi perubahan di segala aspek pada kampung ini. Seperti, perubahan pola pikir masyarakat yang awalnya masyarakat tidak peduli akan Styrofoam bekas sekarang menjadi peduli.

Perubahan status ekonomi juga terjadi dengan adanya pemanfaatan styrofoam bekas ini. Masyarakat yang awalnya tidak memiliki pekerjaan bisa menjadi pengrajin miniatur pesawat dan secara otomatis semakin banyak masyarakat yang bekerja. Maka, perekonomian di kampung tersebut akan meningkat. Perubahan tatanan kampungnya terjadi seiring peningkatan daya kreatifitas masyarakat Kampung Wisata, Mojosongo karena masyarakat akan terbiasa untuk membuat kerajinan-kerajinan dengan model yang berbeda-beda. Selain itu, akan terjadi peningkatan Sumber daya manusia di Kampung wisata, Mojosongo. Pengangguran yang ada di kampung wisata Mojosongo akan mengalami penurunan. Jika pemasaran produk kerajinan miniatur pesawat terbang sudah menyebar di pasaran, maka pendapatan masyarakat Kampung wisata, Mojosongo akan mengalami peningkatan. Tidak hanya pendapatan dari penjualan, akan tetapi pendapatan dari kunjungan-kunjungan wisatawan yang penasaran akan kampung tersebut.

Penelitian tentang kampung wisata sudah pernah dilakukan oleh banyak peneliti sebelumnya. Misalnya saja Desa Wisata Pentingsari yang terletak di Kelurahan Umbulharjo, Kecamatan Cangkringan, Kabupaten Sleman, DIY. Berdasarkan penelitian yang sudah dilakukan didapatkan data bahwa sejak April 2008 hingga Oktober 2013 Desa Wisata Pentingsari telah dikunjungi sebanyak 90.000 wisatawan. Banyaknya

${ }^{4}$ Budi Benedictus, "10 Ide Kreatif Memanfaatkan Kembali Styrofoam Bekas," Mobgenic, last modified 2018, accessed September 6, 2019, https://www.mobgenic.com/10-ide-kreatif-memanfaatkan-kembalistyrofoam-bekas/. 
kunjungan wisatawan menjadi salah satu penyebab Desa Wisata Pentingsari dianugerahi beberapa penghargaan tingkat nasional maupun tingkat internasional.

\section{Metode Pendampingan}

Metode yang digunakan dalam kegiatan ini adalah metode PAR (Participation Action Research). Participatory Action Research (PAR) adalah metode riset yang dilaksanakan secara partisipatif di antara warga masyarakat dalam suatu komunitas aras bawah yang semangatnya untuk mendorong terjadinya aksi-aksi transformatif melakukan pembebasan masyarakat dari belenggu ideologi dan relasi kekuasan atau perubahan kondisi hidup yang lebih baik ${ }^{5}$.

Secara umum, metode PAR terbagi dalam dua tipe, yakni Eksplanatif dan Tematik. PAR Eksplanatif memfasilitasi komunitas/masyarakat untuk berpartisipasi dalam menganalisis kebutuhan, permasalahan, dan solusinya sebelum merencanakan aksi transformatif. Sedangkan PAR Tematik menganalisis program aksi transformatif yang sudah berjalan, sebagai alat evaluasi dan pengamatan ${ }^{6}$.

Ruang lingkup kegiatan pendampingan pengabdian ini adalah masyarakat kampung RW 2, Debegan Mojosongo Kota Surakarta bersama relawan rumah baca Rimba Mojosongo. Tim pengabdian melibatkan diri langsung ke lapangan melalui tim yang sudah dibentuk untuk mencari data etnografi yang diinginkan. Proses wawancara yang mendalam akan dilakukan petugas lapangan untuk mendapatkan gambaran tentang motivasi dan keuntungan perajin miniature pesawat dalam mengupayakan pemberdayaan ekonomi masyarakat, serta bagaimana peran masyarakat RW 2 Debegan, Mojosongo dalam mendukung kegiatan tersebut.

Peran masyarakat yang dinilai bisa memberikan gambaran tersebut adalah warga kampung Debegan, ketua RW, RT, PKK, dan remaja-remaja yang tergabung dalam Komunitas Baca Rimba Mojosongo. Proses pencarian data ini akan dilakukan oleh tim lapangan pengabdian LP2M dengan membawa guidebook yang dibuat sebagai panduan untuk mendapatkan data yang diinginkan. Dengan demikian, proses etnografi dalam melihat sejauh mana peran masyarakat dalam mendukung kegiatan optimalisasi limbah Styrofoam ini dapat didapatkan gambaran yang komprehensif.

\section{Implementasi Pendampingan Masyarakat}

Sebelum pelaksanaan pengabdian, tim melaksanakan observasi awal dan wawancara kepada masyarakat sekitar wilayah pengabdian dan pengumpulan data dari

5 Rambo Cronika Tampubolon, "Participatory Action Research (PAR)," LBH Jakarta, last modified 2013, accessed November 8, 2019, https://www.bantuanhukum.or.id/web/participatory-actionresearch-par/.

6 Ibid. 
penelitian terdahulu terkait warga Debegan. Kegiatan ini bertujuan untuk mengetahui kondisi sosial, ekonomi, dan budaya masyarakat sekitar.

Dari data awal, komunitas dampingan Warga kampung Debegan dan khususnya para remaja yang tergabung dalam Komunitas Rumah Baca Rimba Mojosongo memiliki komitmen yang kuat dalam pelestarian lingkungan dan enterpreneurship. Dengan menggandeng 3 sektor dalam pelestarian lingkungan (sekolah, keluarga dan lingkungan masyarakat), komunitas ini aktif untuk terus melakukan edukasi bersama dalam bidang lingkungan dan enterpreneurship. ${ }^{7}$ Hasil kajian Johan Jatu Wibawa Putra tentang Jaringan Sosial Pengusaha Tempe di Debegan ini semakin melengkapi bagaimana gambaran social masyarakat yang memiliki semangat gotong royong dan bekerjasama dengan memanfaatkan SDM yang ada dalam pengembangan enterpreseurship. ${ }^{8}$

Oleh karena itu, maka pendampingan pemanfaatan styrofoam ini selaras dengan semangat mereka dalam pelestarian lingkungan dan enterpreseurship dan menjadi warna baru bagi masyarakat dan Komunitas Rumah Baca Rimba untuk memanfaatkan limbah Styrofoam bekas menjadi miniatur pesawat. Agar pendampingan ini memiliki dampak positif yang baik bagi komunitas dampingan, maka keterlibatan mereka sejak awal dalam implementasi program ini menjadi kunci utama. Selain itu adanya dukungan ketua RW dan stakeholder masyarakat yang menyambut baik kegiatan ini semakin mempermudah an memperlancar agenda kegiatan tersebut.

Untuk mempersiapkan pelaksanaan kegiatan ini, Tim pengabdi telah melakukan beberapa kali rapat koordinasi dengan masyarakat dan relawan wilayah kampung RW 2 yang tergabung dalam Komunitas Baca Rimba Mojosongo untuk membahas terkait teknis acara kegiatan, penentuan kepesertaan dari masyarakat, bahan-bahan pelatihan miniatur pesawat, serta analisa dan dampak sosial tentang kegiatan ini. Dengan demikian, maka sejak awal komunitas dampingan sudah aktif dan terlibat secara mandiri dalam perencanaan sampai implementasi program.

Implementasi pendampingan pemanfaatan limbah Styrofoam bekas menjadi miniature pesawat dilakukan dengan model pelatihan dan praktek pembuatan yang difasilitasi oleh Bapak Sudarmaji, seorang warga setempat di Desa Debegan. Keterlibatan warga setempat untuk menjadi fasilitator ini menjadi kunci agar masyarakat Desa Debegan dapat saling mendukung dalam tata kelola lingkungan berkelanjutan dan sekaligus mengasah entrepreneurship, baik bagi warga Debegan maupun anggota Komunitas Rumah Baca Rimba Mojosongo.

Dalam implementasi pendampingan ini dilakukan dengan beberapa tahap, dimulai dengan pertemuan tatap muka dengan metode ceramah dan demonstrasi.

${ }^{7}$ Alditya Nuari Karno, "Pengaruh Tindakan Spiritual Emotional Freedom Technique (SEFT) terhadap Jiwa Entrepreneurship Komunitas Rimba Debegan Mojosongo Kota Surakarta” (IAIN SURAKARTA, 2020).

8 Johan Jatu Wibawa Putra, "Jaringan Sosial Pengusaha Tempe Dalam Kelangsungan Usaha Di Debegan” (UNS (Sebelas Maret University), 2010). 
Dalam kegiatan ini diikuti warga masyarakat kampung RW 2 Debegan, Mojosongo dengan jumlah peserta mencapai 22 orang perwakilan. Hal ini menunjukkan bahwa warga Debegan memiliki animo yang bagus untuk belajar bersama bagaimana memanfaatkan limbah Styrofoam bekas menjadi miniature pesawat. Adapun materi yang dibahas bersama dalam kegiatan ini meliputi: (1) Pengantar kerajinan tepat guna; (2) Pemanfaatan barang-barang tidak terpakai khususnya terkait limbah Styrofoam; (3) Praktik pelaksanaan pembuatan miniature pesawat dari limbah Styrofoam; (4) Strategi marketing; dan (5) Online marketing untuk bekal bagi warga dalam penjualan hasil kerajinan tangan miniature pesawat yang telah mereka hasilkan.

Tahap berikutnya adalah praktek pembuatan miniature pesawat dari limbah Styrofoam bekas. Para peserta berlatih bagaimana memilih material limbah Styrofoam yang bisa dimanfaatkan dalam miniature pesawat, serta latih bersama tentang penyusunan desain dan pembuatan miniature pesawat. Tahap ini dilaksanakan 3 kali pertemuan, sehingga standar minimal kualitas produk hasil karya miniature pesawat dapat sesuai dengan standar baik dan layak jual.

Hasil evaluasi yang dilakukan oleh Tim pendamping terkait agenda ini menunjukkan bahwa program ini memiliki nilai kemanfaatan bagi warga Debegan. Hal ini terlihat dari keterlibatan mereka, mulai dari perencanaan sampai proses praktek pembuatan miniatur pesawat dari limbah Styrofoam yang tetap konsisten, walau dilakukan banyak pertemuan yang berbeda-beda selama tiga bulan. Selain itu, juga terlihat dari pasca program didapatkan peserta terus mengimplementasikan pembuatan miniatur pesawat di rumah masing-masing pasca agenda kegiatan. Terkait dengan evaluasi hasil produk dapat dikatakan cukup baik, karena setap peserta telah mampu mendemonstrasikan pembuatan miniature pesawat meskipun masih kurang rapi dalam hal pengerjaannya.

Dengan tingginya antusiasme masyarakat kampung Debegan serta didukung oleh perangkat pemerintahan setempat. kegiatan ini memiliki peluang untuk menjadikan kampung Debegan sebagai sebuah kampung vokasi yang ada di Kota Surakarta. Untuk menunjang kegiatan dan keberlanjutan kegiatan perlu diadakan kegiatan lanjutan pelatihan miniature pesawat ini, yakni memperkuat skill pemasaran serta pengembangan jaringan agar dapat mengembangkan peluang bisnis dan pemberdayaan hasil produk miniatur pesawat dari limbah Styrofoam.

\section{Pembahasan}

Implementasi pemberdayaan ekonomi kreatif melalui pemanfaatan limbah Styrofoam menjadi barang bernilai ekonomis ini menjadi salah satu pilihan dalam mereduksi timbulan sampah Styrofoam. Melalui pendekatan PAR di atas, warga Dusun Debegan telah membuktikan bahwa mereka memiliki komitment dan kepedulian yang baik dalam pelestarian lingkungan. 
Dalam banyak kajian, pemanfaatan limbah Styrofoam menjadi produk baru telah banyak diulas dalam berbagai berita, laporan penelitian ataupun jurnal ilmiah. Sebagaimana disajikan dalam latar belakang di atas, pemanfaatan limbah Styrofoam menjadi produk baru di Jepang telah menjadi model dan dikenal dengan Styrogami. Di Indonesia, limbah Styrofoam ini telah dimanfaatkan menjadi berbagai produk, baik sebagai suplemen dari suatu produk, misalnya menjadi bahan pencampur beton, batako atau campuran panel dinding, ${ }^{9}$ memanfaatkan Styrofoam sebagai media penanaman hidroponik, ${ }^{10}$ atau diolah kembali menjadi produk baru handycraft, seperti pembuatan fashion, ${ }^{11}$ bingkai foto, ${ }^{12}$ dan miniatur pesawat yang dibuat oleh Warga Debegan ini.

Kegiatan pendampingan ini menjadi nilai tambah ekonomi sekaligus menjadi salah satu solusi untuk mengurai permasalahan timbulan sampah di dusun Debegan. Pelaksanaan program yang direncanakan, diimpleementasikan dan dievaluasi oleh Warga Debegan menjadi kunci penting agar kegiatan ini terus berkembang dan berkelanjutan sehingga mampu mendukung Program Kota Surakarta dalam program kampung vokasi dengan mengembangkan kawasan kampung wisata sentra kerajinan miniatur pesawat ramah lingkungan.

\section{Kesimpulan}

Kegiatan pembuatan miniatur pesawat berbahan limbah Styrofoam ini mendapatkan respon yang positif dari masyarakat dukuh Debegan, Mojosongo. Terbukti peserta yang berpartisipasi dalam kegiatan ini tetap konsisten mengikuti setiap tahapan pendampingan yang telah dilaksanakan . Kegiatan ini juga memberikan alternatif lain pada masyarakat dalam hal pengelolaan limbah Styrofoam agar memiliki

9 Khairul Miswar, “Beton Ringan Dengan Menggunakan Limbah Styrofoam,” Portal: Jurnal Teknik Sipil 10, no. 1 (2018); Reni Suryanita, Iskandar Romey Sitompul, and Zunwanis Zunwanis, "Karakteristik Kuat Lentur Beton Ringan Akibat Penambahan Styrofoam Pada Desain Campuran Beton," Jurnal Sains dan Teknologi 13, no. 1 (2014); Andi Prasetiyo Wibowo and Ir Suprapto Siswosukarto, "Penggunaan Beton Styrofoam Dengan Perkuatan Wiremesh Untuk Panel Dinding Tebal 7 Cm" (Universitas Gadjah Mada, 2011); Wahyu Anggoro, "Karakteristik Batako Ringan Dengan Campuran Limbah Styrofoam Ditinjau Dari Densitas, Kuat Tekan Dan Daya Serap Air" (Universitas Negeri Semarang, 2014); Agus Santoso, Slamet Widodo, and Faqih Ma'arif, "Pemanfaatan Limbah Styrofoam (Expanded Polysterene) Untuk Pembuatan Dinding Struktural Beton Ringan Ramah Lingkungan," Informasi dan Ekspose hasil Riset Teknik SIpil dan Arsitektur 7, no. 1 (2011); Iqbal Fadhilah Warani, "Pengaruh Penambahan Limbah Styrofoam Dan Flyashterhadap Berat Jenis Dan Kuat Tekan Beton Ringan Struktural" (2014); Andy Mizwar et al., "Pemanfaatan Lumpur Marmer, Limbah Styrofoam Dan Abu Layang Batubara Untuk Pembuatan Bata Beton Berlubang," Jurnal Intekna (in Indonesian) 12, no. 1 (2015): 1-8; Abdul Halim, "Pengaruh Pemakaian Limbah Styrofoam Terhadap Kuat Tekan Dan Berat Batako," Widya Teknika 21, no. 1 (2013); Dafid Irawan and M Cakrawala, "Pemanfaatan Limbah Styrofoam Dalam Pembuatan Material Dinding Bangunan," Widya Teknika 23, no. 2 (2015).

10 Teti Febrianti et al., "Pemanfaatan Limbah Styrofoam Untuk Media Hidroponik," Journal of Agrifish 1, no. 1 (2019): 37-44.

11 Sandra Khairunnisa and Arini Arumsari, "Pengolahan Limbah Styrofoam Menjadi Produk Fashion," eProceedings of Art \& Design 3, no. 2 (2016).

12 Allays Pamawati, “Pemanfaatan Limbah Styrofoam Menjadi Bingkai Foto” (2019). 
nilai manfaat dan tidak menjadi beban timbulan sampah di Dusun tersebut. Pendampingan ini juga memiliki potensi untuk menjadikan kampung Debegan Mojosongo sebagai kampung miniatur pesawat serta menciptakan kawasan kampung wisata sentra kerajinan miniatur pesawat.

Rekomendasi dari hasil kajian ini adalah sangat penting untuk dilakukan pendampingan secara kontinyu oleh tim pengabdian dan LP2M IAIN Surakarta untuk dapat dijadikan daerah binaan. Karena dengan pembinaan dan penjagaan potensi, maka tujuan kampung miniatur pesawat ini dapat diwujudkan dalam rangka untuk memperkuat pemberdayaan ekonomi, sosial, dan budaya masyarakat setempat. Hal ini sesuai dengan semangat kota Surakarta yang mendeklarasikan sebagai kota vokasi. Selain itu, dari hasil pendampingan ini sangat penting untuk dilakukan penguatan pemasaran produk-produk yang telah mereka hasilkan, sehingga diharapkan kampung vokasi miniatur pesawat di Dusun Debegan dapat terwujud.

\section{Daftar Referensi}

Anggoro, Wahyu. "Karakteristik Batako Ringan Dengan Campuran Limbah Styrofoam Ditinjau Dari Densitas, Kuat Tekan Dan Daya Serap Air." Universitas Negeri Semarang, 2014.

Benedictus, Budi. "10 Ide Kreatif Memanfaatkan Kembali Styrofoam Bekas." Mobgenic. Last modified 2018. Accessed September 6, 2019. https://www.mobgenic.com/10ide-kreatif-memanfaatkan-kembali-styrofoam-bekas/.

Fathurrohman, Amang, M Daimul Abror, Zainul Ahwan, Lukman Hakim, Syukur Sugeng Apriwiyanto, and Mulyono Wibisono. Inisiasi Tata Kelola Manajemen Bank Sampah Berbasis IT Pada Komunitas Bank Sampah Berbasis Sekolah, Pemuda, Dan Masyarakat Di Kabupaten Pasuruan. Kabupaten Pasuruan, 2018.

Febrianti, Teti, Fadilla Aini, Andriansyah Andriansyah, and Puteri Galura Asih. "Pemanfaatan Limbah Styrofoam Untuk Media Hidroponik." Journal of Agrifish 1, no. 1 (2019): 37-44.

Halim, Abdul. "Pengaruh Pemakaian Limbah Styrofoam Terhadap Kuat Tekan Dan Berat Batako." Widya Teknika 21, no. 1 (2013).

Irawan, Dafid, and M Cakrawala. "Pemanfaatan Limbah Styrofoam Dalam Pembuatan Material Dinding Bangunan." Widya Teknika 23, no. 2 (2015).

Karno, Alditya Nuari. "Pengaruh Tindakan Spiritual Emotional Freedom Technique (Seft) Terhadap Jiwa Entrepreneurship Komunitas Rimba Debegan Mojosongo Kota Surakarta." IAIN SURAKARTA, 2020.

Khairunnisa, Sandra, and Arini Arumsari. "Pengolahan Limbah Styrofoam Menjadi Produk Fashion." eProceedings of Art \& Design 3, no. 2 (2016).

Miswar, Khairul. "Beton Ringan Dengan Menggunakan Limbah Styrofoam." Portal: Jurnal Teknik Sipil 10, no. 1 (2018). 
Mizwar, Andy, Erika Agustini, Gilang Samudra, and M Auliannoor. "Pemanfaatan Lumpur Marmer, Limbah Styrofoam Dan Abu Layang Batubara Untuk Pembuatan Bata Beton Berlubang." Jurnal Intekna (in Indonesian) 12, no. 1 (2015): 1-8.

Pamawati, Allays. "Pemanfaatan Limbah Styrofoam Menjadi Bingkai Foto” (2019).

Putra, Johan Jatu Wibawa. "Jaringan Sosial Pengusaha Tempe Dalam Kelangsungan Usaha Di Debegan.” UNS (Sebelas Maret University), 2010.

Repository

ugm.

"Http://Www.Pnpm-

Mandiri.Org/Index.Php?Option=com_content\&view=article\&id=35:978-Desa-" (2009): 1-15.

Santoso, Agus, Slamet Widodo, and Faqih Ma'arif. "Pemanfaatan Limbah Styrofoam (Expanded Polysterene) Untuk Pembuatan Dinding Struktural Beton Ringan Ramah Lingkungan." INformasi dan Ekspose hasil Riset Teknik SIpil dan Arsitektur 7, no. 1 (2011).

Soekanto, Soerjono. Teori Sosiologi Tentang Perubahan Sosial. Ghalia Indonesia, Jakarta, 1983.

Suryanita, Reni, Iskandar Romey Sitompul, and Zunwanis Zunwanis. "Karakteristik Kuat Lentur Beton Ringan Akibat Penambahan Styrofoam Pada Desain Campuran Beton." Jurnal Sains dan Teknologi 13, no. 1 (2014).

Tampubolon, Rambo Cronika. “Participatory Action Research (PAR).” LBH Jakarta. Last modified 2013. Accessed November 8, 2019. https://www.bantuanhukum.or.id/web/participatory-action-research-par/.

Warani, Iqbal Fadhilah. "Pengaruh Penambahan Limbah Styrofoam Dan Flyashterhadap Berat Jenis Dan Kuat Tekan Beton Ringan Struktural” (2014).

Wibowo, Andi Prasetiyo, and Ir Suprapto Siswosukarto. "Penggunaan Beton Styrofoam Dengan Perkuatan Wiremesh Untuk Panel Dinding Tebal 7 Cm." Universitas Gadjah Mada, 2011.

Wisnuputri, Aninditya, Denny Nurkertamanda, and Wiwik Budiawan. "Pemanfaatan Limbah Organik Tumbuhan Dan Hifa Fungi Rhizopus Sp. Pada Struktur Bantalan Kemasan Barang Dengan Metode Eksperimen Faktorial" 3 (2014). 